\title{
Identification of Quantitative Loci for Tolerance to Barley Yellow Dwarf Virus in Oat
}

\author{
Hua Jin, Leslie L. Domier, Frederic L. Kolb, and Charles M. Brown
}

First, second, third, and fourth authors: Department of Crop Sciences, University of Illinois, 1102 South Goodwin Avenue, Urbana 61801; second author: United States Department of Agriculture, Agricultural Research Service, Crop Protection Research Unit, 1102 South Goodwin Avenue, Urbana, IL 61801.

Accepted for publication 15 January 1998.

\section{ABSTRACT}

Jin, H., Domier, L. L., Kolb, F. L., and Brown, C. M. 1998. Identification of quantitative loci for tolerance to barley yellow dwarf virus in oat. Phytopathology 88:410-415.

Molecular markers linked to quantitative trait loci conditioning tolerance to barley yellow dwarf virus (BYDV) were identified in oat (Avena sativa) using amplified fragment length polymorphism (AFLP) analysis. Near-isogenic and recombinant inbred lines (NILs and RILs, respectively) derived from a cross of Clintland64 (BYDV-sensitive) and IL86-5698 (BYDV-tolerant) were evaluated for their responses to an Illinois isolate of the PAV strain of BYDV. Individual markers identified in the analysis of the NILs explained up to $35 \%$ of the variability seen in the tolerance response. Single-point analysis of the marker data from the RIL population identified 24 markers in three linkage groups that were associated with tolerance to BYDV infection at $P \leq 0.001$. These markers defined three major loci, A, C, and E, that were contributed by the tolerant parent (IL86-5698) and explained 35.0, 20.6, and $17.0 \%$ of the variability, respectively. Three minor loci $\left(\mathrm{G}, \mathrm{H}_{1}\right.$, and $\left.\mathrm{R}\right)$ were identified at $P \leq 0.01$. These loci were contributed by the sensitive parent (Clintland64) and explained $5.8,5.6$, and $5.6 \%$ of the variability, respectively. Interval analysis showed that only the loci A, C, and E are associated significantly with BYDV tolerance at $\log$ of the likelihood ratio $\geq 3$.0. These loci explained about $50 \%$ total of the variation in BYDV tolerance in multimarker regression analysis in both years. The BYDV tolerance loci A, C, E, and R were mapped to hexaploid oat restriction fragment length polymorphism linkage groups $2,8,36$, and 5, respectively, by analyzing the segregation of the AFLP markers in the Kanota $\times$ Ogle RIL population.

Additional keywords: comparative mapping.
Barley yellow dwarf (BYD) is caused by a group of luteoviruses collectively referred to as the barley yellow dwarf viruses (BYDVs). BYDVs are obligately aphid-transmitted and have broad host ranges, including all of the major cereal crops (rice, maize, wheat, barley, oat, and rye) and many annual and perennial lawn, weed, pasture, and range grasses (12). Characteristic symptoms of BYDV-infected oat (Avena sativa L.) plants are stunted growth, leaf discoloration, and blasting of florets (18). The most effective way to limit economic losses from this disease is by planting resistant or tolerant cultivars (3).

In barley (Hordeum vulgare L.), a recessive resistance gene, $y d l$, was identified in the cultivar Rojo (48), but it was rarely used in plant breeding programs because it confers a low level of resistance. A semidominant resistance gene, $Y d 2$, was identified in Ethiopian barley and mapped to the long arm of chromosome 3, based first on morphological markers and more recently on restriction fragment length polymorphism (RFLP) markers $(8,43)$. Allelic variability at the $Y d 2$ gene locus also has been reported (5). Two polypeptide markers were identified that cosegregated with the $Y d 2$ gene (22). The $Y d 2$ gene confers a high level of resistance and has been widely used in plant breeding programs (13). In bread wheat (Triticum aestivum L.), a semidominant tolerance gene, $B d v 1$, has been identified in wide crosses with Agropyron (46).

Corresponding author: L. L. Domier; E-mail address: 1-domier@uiuc.edu

The use of a brand name product by the United States Department of Agriculture implies no approval of the product to the exclusion of others that also may be suitable.

Publication no. P-1998-0223-01R

This article is in the public domain and not copyrightable. It may be freely reprinted with customary crediting of the source. The American Phytopathological Society, 1998.
In oat, the terms "tolerant" and "sensitive," as defined by Cooper and Jones (11), have been used to describe the host responses to infection by the PAV strain of BYDV. BYDV-PAV invades and replicates in the tissues of both tolerant and sensitive oat lines, but tolerant lines do not develop severe disease symptoms. When compared with obviously diseased plants, some tolerant oat lines have significantly reduced concentrations of BYDV coat protein (17) and, hence, can be termed resistant to virus multiplication (5). There is no evidence of a hypersensitive or localized necrotic resistance response to BYDV infection in oat, and no single major resistance or tolerance gene has been identified in oat (3). High levels of tolerance to BYDV infection have been identified in oat and shown to be conditioned by the interaction of two to four genes $(26,32)$. Hence, like many complex disease resistance phenotypes, tolerance to BYDV infection appears to be inherited quantitatively in oat.

With the introduction of molecular marker technologies, it has become possible to map and study the interaction of quantitative trait loci (QTL) and their role in disease resistance (59). QTL mapping has been used in several species to study the genetics of agronomic and disease resistance traits $(4,9,10,40,41,49,58,59)$. Once high levels of polygenic tolerance or resistance have been developed in germ plasm lines, it can be time- and labor-consuming to move all of the genes for the phenotype into new cultivars. This is especially true for BYDV tolerance, in which it is necessary to inoculate plants by infesting them with aphids harboring BYDV. The use of molecular markers during selection has the potential to speed the transfer of genes controlling complex traits into new lines.

A RFLP map for cultivated oat has been described and used to identify QTL linked to physiological traits and quantitative agronomic traits $(21,36,47)$. Stem rust resistance genes were localized on linkage groups 3 and 4 (35). Recently, aneuploid lines have been used to assign some RFLP markers and linkage groups to physical chromosomes (24). The usefulness of the hexaploid oat 
RFLP map has been extended further by advances in comparative mapping of cereals $(14,52)$, which may make it possible to take advantage of developments in other genome mapping programs such as those of rice, maize, and barley.

Amplified fragment length polymorphism (AFLP) analysis is a DNA fingerprinting technique that is based on the selective polymerase chain reaction (PCR) amplification of restriction fragments from a total restriction digest of genomic DNA (56). The number of restriction fragments amplified is determined by the complexity of the template and the number of selective nucleotides at the $3^{\prime}$ end of the primers. Of the four most commonly used DNA-based mapping techniques-AFLP, RFLP, random amplified polymorphic DNA (RAPD), and microsatellite-AFLP has the highest multiplex ratio, which defines the number of loci (or bands) that can be simultaneously analyzed in one experiment, and is considered a promising marker system for mapping $(29,38)$. Since it was reported, the AFLP technique has been applied to analysis of genetic diversity $(6,16,20,31,37,51,55)$, construction of linkage maps $(2,44$, 54), mapping specific genes $(45,50)$, and positional cloning (7).

Near-isogenic lines (NILs), produced through backcrossing to the recurrent parent, are common tools used to study lines differing primarily in the chromosomal region of a particular trait of interest. NILs have been used to identify markers linked to important plant resistance genes $(1,30,42)$. In this study, we used AFLP analysis of three pairs of NILs and two recombinant inbred line (RIL) populations to identify and map DNA markers related to BYDV tolerance in cultivated oat.

\section{MATERIALS AND METHODS}

Plant materials. A population of 126 RILs was derived from an $\mathrm{F}_{2}$ population of a cross of Clintland64 (BYDV-sensitive) and IL86-5698 (BYDV-tolerant) through single-seed descent for four generations. The tolerance of $F_{7}$ and $F_{8}$ lines to BYDV infection was evaluated in 1995 and 1996 in inoculated hills grown in the field at the University of Illinois Crop Sciences Research and Education Center. Plant height at maturity and days to heading were evaluated in uninfected $F_{8}$ plants grown in the field in 1996. For the BYDV evaluations, replicated hills with 15 plants per hill were planted each year in a randomized complete block design. Hills were inoculated at Feekes growth stage 1 or 2 (27) by infesting them with Rhopalosiphum padi (L.) aphids harboring an Illinois isolate of BYDV-PAV (19). Inoculation was carried out by dispensing an equal volume of an aphid/corn meal mixture onto each hill so that essentially all of the plants in a hill were infected. In 1995, two investigators independently evaluated both replications of hills at Feekes growth stage 10.5 and again at growth stage 10.7. The means of the eight evaluations (two evaluators $\times$ two times $\times$ two replicates) were used as the phenotypic value in the analyses with molecular marker data. Since there was excellent agreement among the ratings taken by different evaluators and at different times in

TABLE 1. Sequences of amplified fragment length polymorphism primers used for selective amplifications

\begin{tabular}{|c|c|c|c|}
\hline Primers & $\begin{array}{l}\text { EcoRI core } \\
\text { sequence }^{\mathrm{y}}+\end{array}$ & Primers & $\begin{array}{c}\text { Mse I core } \\
\text { sequence }^{\mathrm{Z}}+\end{array}$ \\
\hline EcoRI1 (e1) & $-\mathrm{AAC}$ & Mse I1 (m1) & -CAA \\
\hline EcoRI2 (e2) & $-\mathrm{AAG}$ & Mse $\mathrm{I} 2(\mathrm{~m} 2)$ & $-\mathrm{CAC}$ \\
\hline EcoRI3 (e3) & $-\mathrm{ACA}$ & Mse I3 (m3) & $-\mathrm{CAG}$ \\
\hline EcoRI4 (e4) & $-\mathrm{ACC}$ & MseI4 (m4) & $-\mathrm{CAT}$ \\
\hline EcoRI5 (e5) & $-\mathrm{ACG}$ & Mse I5 (m5) & -CTA \\
\hline EcoRI6 (e6) & -ACT & MseI6 (m6) & $-\mathrm{CTC}$ \\
\hline EcoRI7 (e7) & $-\mathrm{AGC}$ & MseI7 (m7) & $-\mathrm{CTG}$ \\
\hline EcoRI8 (e8) & $-\mathrm{AGG}$ & Mse I8 (m8) & -CTT \\
\hline EcoRI9 (e9) & -AAT & & \\
\hline EcoRI10 (e10) & -ATC & & \\
\hline
\end{tabular}

y EcoRI primer core sequence: 5'-GACTGCGTACCAATTC-3'.

${ }^{z}$ MseI primer core sequence: 5'-GATGAGTCCTGAGTAA-3'.
1995, three replicates were planted in 1996 and rated only once at Feekes growth stage 10.6. The means of the three replications were used as the phenotypic value in the analyses with the molecular marker data. The 0 to 9 BYDV ratings were assigned based on leaf chlorosis, stunting, and blasting of the florets in the panicles (39). On this scale, hills rated 0 exhibit no leaf discoloration, no blasting, and no stunting. Hills rated 9 fail to head and are stunted so severely that the plants are almost dead. If any panicles are observed, essentially all spikelets are blasted. The level of infection in all hills was greater than $90 \%$. The susceptible checks (i.e., Clintland64) generally failed to head and were stunted severely.

Oat (A. sativa) lines near-isogenic for tolerance to BYDV were generated using Clintland64 as the recurrent parent and IL86-5698 as the donor parent. Tolerant plants were backcrossed to the sensitive parent Clintland64 and three pairs of $\mathrm{BC}_{5} \mathrm{~F}_{8}$ NILs were selected for analysis. The tolerant NILs had average ratings of 2.5 or lower, and the sensitive NILs had average ratings of 8.0 or higher. The development of the population of Kanota $\times$ Ogle RILs was described previously (36). The broad-sense heritability of the BYD severity ratings was estimated as described by Nyquist (34).

Isolation of genomic DNA. Genomic DNA was extracted from each of the three pairs of NILs and 126 RILs of Clintland64 $\times$ IL86-5698, as well as the parents, with cetyltrimethylammonium bromide (CTAB) (15) and dissolved in $10 \mathrm{mM}$ Tris-HCl, $\mathrm{pH} \mathrm{8.0,}$ and $1 \mathrm{mM}$ EDTA. DNA also was extracted from the 72 RILs of the Kanota $\times$ Ogle population that were used to produce the hexaploid oat RFLP map (36).

AFLP procedure. The AFLP protocol was performed mainly according to the manufacturer's protocol (Life Technologies Inc., Gaithersburg, MD) and that of Vos et al. (56). Primers for AFLP reactions were obtained from Life Technologies Inc. and the University of Illinois Biotechnology Center. Genomic DNA from healthy oat plants was digested with EcoRI and MseI. The digested DNA was preamplified with AFLP primers with one selective nucleotide

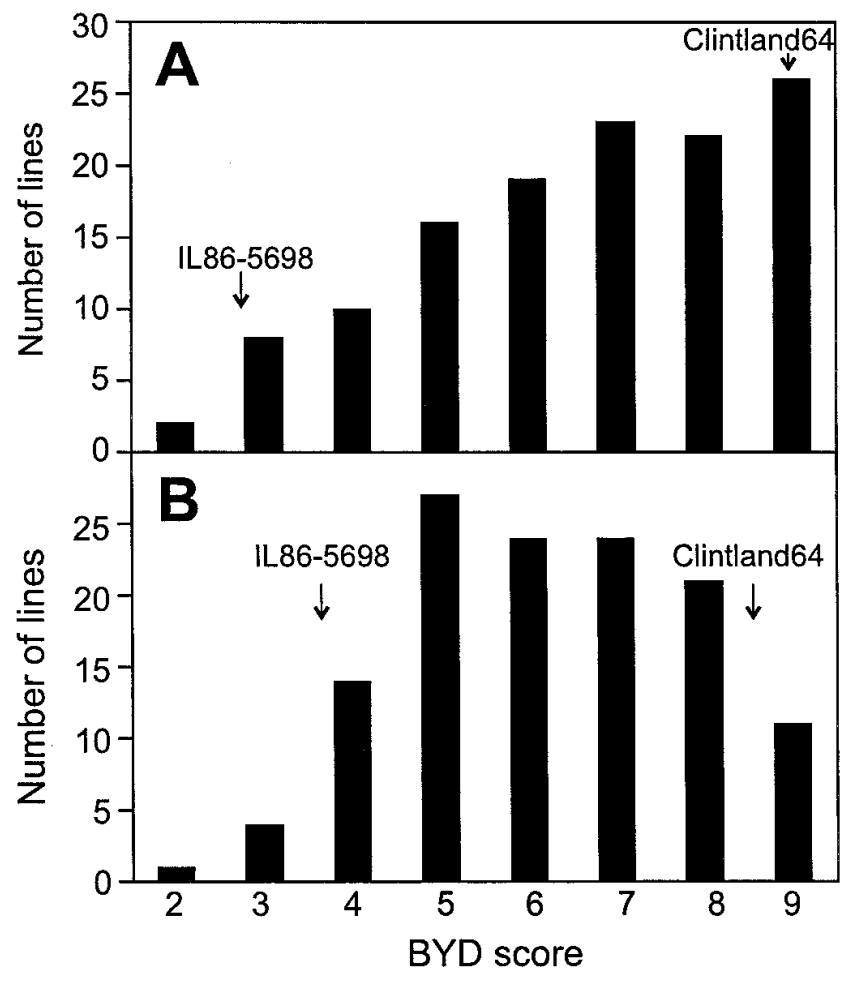

Fig. 1. Distribution of barley yellow dwarf disease severity ratings of recombinant inbred lines from the Clintland64 $\times$ IL86-5698 population. Barley yellow dwarf virus disease severity was rated on hill plots in the field in $\mathbf{A}$, 1995 and B, 1996 based on a 0 to 9 scale, in which 0 is very tolerant and 9 is very sensitive (2). 
(core EcoRI primer + A and core $M s e I+C)$. Diluted preamplified DNA was used as the template for the selective amplification using 80 combinations of AFLP primers with three selective nucleotides each $(E c o$ RI primer + ANN and MseI primer + CNN) (Table 1). The EcoRI primer was end-labeled using $\gamma^{33} \mathrm{P}$-ATP (Andotek, Irvine, CA). Selective amplifications were performed in $10-\mu \mathrm{l}$ reaction volumes with a MJ Research PTC 100 thermal cycler (MJ Research Inc., Watertown, MA) using a touchdown program (56). Products were separated on $43-$ by $52-\mathrm{cm} 5 \%$ denaturing polyacrylamide gels (Long Ranger gel solution; FMC BioProducts, Rockland, ME) at constant power, $70 \mathrm{~W}$, for $1.5 \mathrm{~h}$. Gels were dried and exposed to X-ray films (BioMAX; Eastman Kodak Co., Rochester, NY) at room temperature for 1 to 3 days.

Data analysis. DNA fingerprints were evaluated by visual inspection of autoradiographs. The banding patterns that were associated with tolerance or sensitivity in at least one pair of NILs were labeled with an "n." The presence of a band was scored as " 3 ," the absence as " 1 ," and missing data as " 2 ." Initial singlepoint analysis of markers was conducted using the linear regression function in EXCEL (Microsoft Corp., Redmond, WA). Linkage analysis and map construction were performed using MAPMAKER software (MAPMAKER/EXP, version 3.0b) (25,28). Since most of the AFLP markers were dominant, for initial placement of markers each was entered twice, once in its original and once in its repulsed state. Markers were first grouped with a log of the likelihood ration (LOD) score of 8 and maximum recombination level of 0.30. A LOD score of 3, maximum recombination level of 0.30 , and three-point analysis were used to order loci within groups. The markers were examined further by interval analysis using QGENE (33) with the "complete missing data" option selected. In interval analysis, a LOD score greater than 3.0 was used to declare the pres- ence of a QTL within a marker interval. Models containing different sets of markers and the interactions between markers were evaluated using the GLM procedure in SAS (SAS Institute, Cary, NC). Selected BYDV tolerance markers were placed on the hexaploid oat RFLP map by analyzing the segregation the bands in the Kanota $\times$ Ogle RIL population. The Kanota $\times$ Ogle AFLP segregation data were combined with the published segregation data for 584 RFLP markers from the Kanota $\times$ Ogle RIL population (36), and linkage relationships were determined with MAPMAKER.

\section{RESULTS}

Field evaluations of RIL population. BYD severity ratings of the parent lines IL86-5698 and Clintland64 were 2.9 and 9.0 in 1995 , and 3.7 and 8.5 in 1996, respectively. BYD severity ratings of the RILs ranged from 1.4 to 9.0 in 1995 and from 2.0 to 9.0 in 1996 (Fig. 1). The means of BYD severity ratings were 6.0 and 6.2 in 1995 and 1996, respectively. The heritability of the BYD severity ratings was 0.80 when the data from both years were combined. The correlation coefficient of BYD severity ratings between the two years was 0.88 . Plant height and maturity were only rated in 1996 and were not significantly $(P \leq 0.05)$ correlated with BYD severity in 1996.

AFLP analysis of NILs and RILs. AFLP fingerprints were generated for the parents and three pairs of NILs using 80 primer combinations. Each combination produced an average of about 100 bands. Approximately $10 \%$ of the bands were polymorphic among the parents. Six banding patterns were identified that were associated with all three tolerant NILs, but not with the sensitive NILs; 23 banding patterns differed in two pairs; and 68 banding patterns differed in only one pair of NILs. Based on this informa-

TABLE 2. Single marker regression and linkage groups of identified amplified fragment length polymorphism markers associated with barley yellow dwarf virus (BYDV) tolerance

\begin{tabular}{|c|c|c|c|c|c|c|}
\hline \multirow[b]{2}{*}{ Marker } & \multicolumn{2}{|c|}{ BYDV-95 } & \multicolumn{2}{|c|}{ BYDV-96 } & \multirow[b]{2}{*}{ Locus $^{\mathrm{w}}$} & \multirow[b]{2}{*}{ Oat group ${ }^{\mathrm{x}}$} \\
\hline & $R^{2}$ & $P>F$ & $R^{2}$ & $P>F$ & & \\
\hline$e 2 m 3-2 n^{y}$ & 0.350 & $2.31 \times 10^{-11}$ & 0.190 & $1.16 \times 10^{-6}$ & A & \\
\hline e9m5-5n & 0.337 & $5.66 \times 10^{-11}$ & 0.181 & $2.13 \times 10^{-6}$ & A & \\
\hline e9m6-1n & 0.335 & $6.66 \times 10^{-11}$ & 0.181 & $2.18 \times 10^{-6}$ & A & \\
\hline e6m6-20n & 0.319 & $1.98 \times 10^{-10}$ & 0.194 & $9.04 \times 10^{-7}$ & A & 2 \\
\hline e9m5-9n & 0.295 & $1.05 \times 10^{-9}$ & 0.179 & $2.42 \times 10^{-6}$ & A & \\
\hline $\mathrm{e} 4 \mathrm{~m} 2-1 \mathrm{fn}$ & 0.288 & $1.67 \times 10^{-9}$ & 0.158 & $1.01 \times 10^{-5}$ & $\mathrm{~A}$ & 2 \\
\hline e6m5-10n & 0.286 & $1.90 \times 10^{-9}$ & 0.179 & $2.48 \times 10^{-6}$ & A & \\
\hline e8m1-9n & 0.271 & $5.27 \times 10^{-9}$ & 0.157 & $1.03 \times 10^{-5}$ & A & \\
\hline e8m3-13 & 0.267 & $7.14 \times 10^{-9}$ & 0.185 & $1.69 \times 10^{-6}$ & A & 2 \\
\hline$e 8 m 8-2 n$ & 0.258 & $1.29 \times 10^{-8}$ & 0.171 & $4.25 \times 10^{-6}$ & A & \\
\hline e1m6-5n & 0.254 & $1.64 \times 10^{-8}$ & 0.147 & $1.98 \times 10^{-5}$ & A & 2 \\
\hline e8m3-10 & 0.245 & $3.03 \times 10^{-8}$ & 0.126 & $7.90 \times 10^{-5}$ & A & 2 \\
\hline e6m4-3 & 0.243 & $3.51 \times 10^{-8}$ & 0.143 & $2.57 \times 10^{-5}$ & A & 2 \\
\hline$e 3 m 7-3 n$ & 0.218 & $1.87 \times 10^{-7}$ & 0.146 & $2.19 \times 10^{-5}$ & A & 2 \\
\hline e6m6-3n & 0.074 & 0.0026 & 0.196 & $8.18 \times 10^{-7}$ & $\mathrm{C}$ & \\
\hline e6m5-5a & 0.053 & 0.0106 & 0.206 & $4.16 \times 10^{-7}$ & $\mathrm{C}$ & \\
\hline e1m3-5 & $\mathrm{n} / \mathrm{s}^{\mathrm{z}}$ & $\mathrm{n} / \mathrm{s}$ & 0.128 & $7.19 \times 10^{-5}$ & $\mathrm{C}$ & \\
\hline e6m6-2n & $\mathrm{n} / \mathrm{s}$ & $\mathrm{n} / \mathrm{s}$ & 0.117 & 0.0001 & $\mathrm{C}$ & \\
\hline e1m6-15a & $\mathrm{n} / \mathrm{s}$ & $\mathrm{n} / \mathrm{s}$ & 0.101 & 0.0004 & $\mathrm{C}$ & \\
\hline e1m6-2 & $\mathrm{n} / \mathrm{s}$ & $\mathrm{n} / \mathrm{s}$ & 0.071 & 0.0032 & $\mathrm{C}$ & 36 \\
\hline e6m4-1a & $\mathrm{n} / \mathrm{s}$ & $\mathrm{n} / \mathrm{s}$ & 0.071 & 0.0031 & $\mathrm{C}$ & 36 \\
\hline$e 2 m 3-2 a$ & 0.170 & $4.43 \times 10^{-6}$ & 0.116 & 0.0002 & $\mathrm{E}$ & \\
\hline e2m3-3 & 0.164 & $6.71 \times 10^{-6}$ & 0.093 & 0.0007 & $\mathrm{E}$ & \\
\hline $\mathrm{e} 2 \mathrm{~m} 2-11$ & 0.159 & $9.28 \times 10^{-6}$ & 0.128 & $7.06 \times 10^{-5}$ & $\mathrm{E}$ & \\
\hline $\mathrm{e} 2 \mathrm{~m} 2-12$ & 0.159 & $9.4 \times 10^{-6}$ & 0.115 & 0.0002 & $\mathrm{E}$ & \\
\hline e4m6-7 & 0.119 & 0.0001 & 0.080 & 0.0017 & $\mathrm{E}$ & 8 \\
\hline e6m5-1n & 0.058 & 0.0075 & $\mathrm{n} / \mathrm{s}$ & $\mathrm{n} / \mathrm{s}$ & $\mathrm{E}$ & \\
\hline e8m1-6 & 0.058 & 0.0074 & $\mathrm{n} / \mathrm{s}$ & $\mathrm{n} / \mathrm{s}$ & $\mathrm{G}$ & \\
\hline$e 6 m 5-4 n$ & $\mathrm{n} / \mathrm{s}$ & $\mathrm{n} / \mathrm{s}$ & 0.056 & 0.0088 & $\mathrm{H}_{1}$ & \\
\hline e1m6-14 & $\mathrm{n} / \mathrm{s}$ & $\mathrm{n} / \mathrm{s}$ & 0.056 & 0.0089 & $\mathrm{R}$ & 5 \\
\hline
\end{tabular}

${ }^{w}$ BYDV tolerance locus.

${ }^{x}$ Hexaploid oat restriction fragment length polymorphism linkage group.

$y$ " $n$ " marker segregated with tolerance in at least one pair of near-isogenic lines.

${ }^{\mathrm{z}} \mathrm{n} / \mathrm{s}=$ not significant. 
tion, 26 primer combinations were evaluated in 126 RILs from the Clintland64 $\times$ IL86-5698 population, from which 290 polymorphic bands were scored.

Regression analysis. Based on single-marker linear regression analysis, 24 AFLP markers showed a significant $(P \leq 0.001)$ contribution to tolerance in at least 1 year. There were 19 markers associated with tolerance in 1995 and 23 in 1996 (Table 2). Six additional markers were identified at the less stringent level of $P \leq$ 0.01 (Table 2). In addition, 3 markers were associated with plant height and 18 markers were associated with days to heading at $P \leq$ 0.01 (data not shown).

Linkage analysis. The markers that were significantly associated with BYDV tolerance in single-marker regression analysis were distributed among five linkage groups (A, C, E, G, and R) and one unlinked marker (locus $\mathrm{H}_{1}$ ) at LOD threshold 8.0 (Table 2). The tolerance alleles at the major loci, A, C, and E, were donated by the tolerant parent (IL86-5698). Loci A and E individually explained 35.0 and $17.0 \%$ of the variation in tolerance in 1995 , respectively. In 1996, loci A, C, and E individually explained 19.4, 20.6, and $12.8 \%$ of the variation in tolerance, respectively. The tolerance alleles at the minor loci, $\mathrm{G}$ and $\mathrm{H}_{1}$, were donated by the sensitive parent (Clintland64). Locus $\mathrm{G}$ showed a significant association with BYDV tolerance only in 1995 and explained $5.8 \%$ of the variation. Loci $\mathrm{H}_{1}$ and $\mathrm{R}$ each accounted for $5.6 \%$ of the variation in 1996 . None of the markers linked to the major loci for BYDV tolerance were associated with plant height or days to heading, although the minor locus $\mathrm{R}$ was associated with the days to heading at $P \leq 0.01$.
To place the markers on the hexaploid oat RFLP map, the segregation of 80 bands was analyzed in both the Clintland64 $\times$ IL865698 and Kanota $\times$ Ogle IL populations. About half of the bands that segregated in the Clintland64 $\times$ IL86-5698 population also were polymorphic in the Kanota $\times$ Ogle population. Only those markers that could be mapped at a LOD threshold of 3.0 were used to align the two sets of maps. Markers associated with BYD locus A were linked within $2.5 \mathrm{cM}$ to RFLP marker BCD1851 in linkage group 2 (Fig. 2). RFLP probes CDO270 and BCD342 also are linked to the major BYDV tolerance locus A. Both of these RFLP probes hybridize to chromosome segments linked to oat stem rust resistance genes in diploid oat (35). All four of the markers linked to BYD locus $C$ that could be placed on the Kanota $\times$ Ogle map were located off the bottom of linkage group 36 (Fig. 2). This suggests that BYD locus $\mathrm{C}$ is located on a chromosome segment that is not represented in the Kanota $\times$ Ogle map. Only one marker linked to BYD locus E could be placed on the Kanota $\times$ Ogle map. The marker e4m6-7 mapped off the end of Kanota $\times$ Ogle linkage group 8. Two other AFLP markers that were not polymorphic in the Clintland64 $\times$ IL86-5698 population also mapped to the bottom of linkage group 8 (Fig. 2). Markers from $\mathrm{G}$ and $\mathrm{H}_{1}$ were not polymorphic in the Kanota $\times$ Ogle population. Marker e1m6-14, which is associated with locus $\mathrm{R}$, was linked within $5.99 \mathrm{cM}$ to RFLP marker CDO370 in linkage group 5 (data not shown). Two markers that were associated with days to heading were assigned to linkage group 17 (data not shown).

\section{BYD locus A}

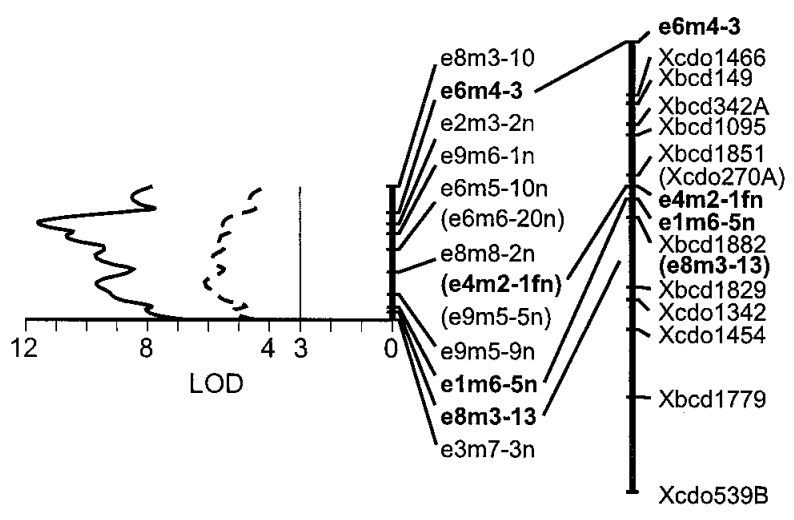

Clintland64 x IL86-5698

Kanota $\times$ Ogle 2

\section{BYD locus C}

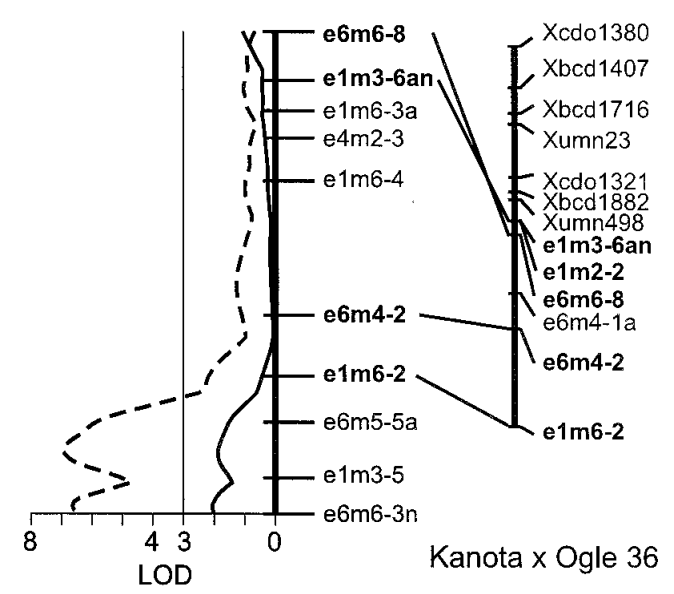

Clintland64 x IL86-5698

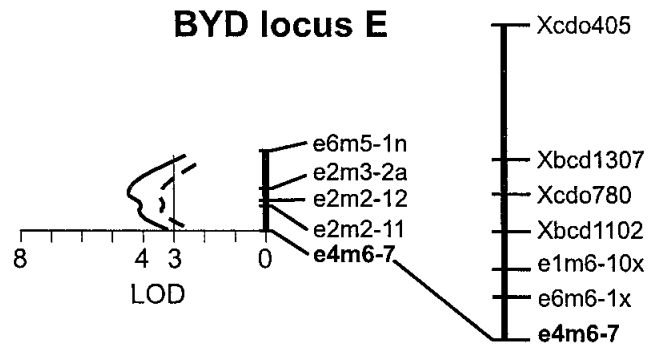

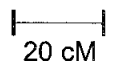

Clintland64 x IL86-5698 Kanota x Ogle 8

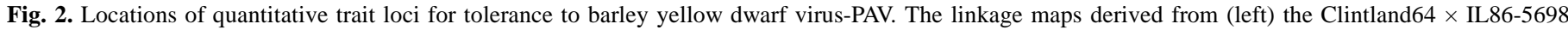

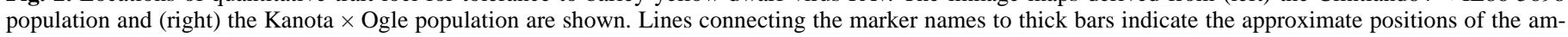

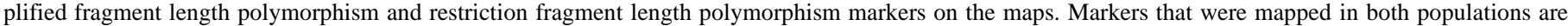

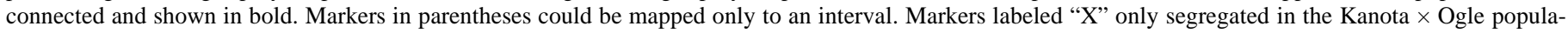

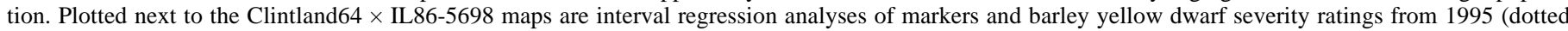
line) and 1996 (solid line). The solid vertical line (LOD = 3.0) indicates the threshold for declaring loci significant. 
QTL and multiple regression analysis. Interval analysis of the markers mapped in the Clintland64 $\times$ IL86-5698 RIL population showed that loci A and E in 1995 and loci A, C, and E in 1996 were significantly (LOD threshold $=3.0$ ) associated with BYDV tolerance (Fig. 2). The single markers with the highest $R^{2}$ values were selected from each of the BYD tolerance groups and subjected to multiple regression analysis. This analysis showed that a model using two markers, e2m3-2n (group A) and e2m3-2a (group E), explained $47 \%$ of the variation in tolerance to BYDV infection in the 1995 field data. A four-marker model using e2m3-2n (group A), e6m5-5a (group C), e2m2-11 (group E), and e6m5-4n $\left(\mathrm{H}_{1}\right)$ explained 50\% of the variation in the 1996 field data. No significant two-way interactions were detected among loci.

\section{DISCUSSION}

In this study, we identified three major QTL for tolerance to BYDV infection in oats. This observation is consistent with the genetic analysis of tolerance to BYDV that has shown that the trait is inherited quantitatively by the interaction of two to four genes $(26,32)$. The contributions of the three major loci varied from year to year. However, loci A and E were associated significantly with tolerance in both years. This may indicate that these two loci are less sensitive to environmental conditions than locus $\mathrm{C}$.

In both years, about $50 \%$ of the phenotypic variability in tolerance to BYDV could be explained by the three loci. Heritability estimates suggest that about $20 \%$ of the variation is due to nongenetic effects. The remaining $30 \%$ variation in the tolerance to BYDV infection may be due to unidentified loci. If the statistical stringency is lowered to $P \leq 0.05$, five additional loci with contributions of about $5 \%$ or less each are identified. Some of these loci also show an association with plant height and maturity. Since the degree of stunting of infected plants is one of the factors considered in rating the severity of BYDV symptoms, this would not be unexpected. However, none of the three major BYDV tolerance loci were associated with plant height or maturity.

The NILs proved to be very useful to identify the major loci of QTL for BYDV tolerance in our study. The six banding patterns that were associated with tolerance or sensitivity in all three pairs of NILs were in linkage group A. In addition, bands that were polymorphic in at least one pair of the NILs were linked to markers in each of the tolerance groups. However, by scoring all of the bands on the AFLP gels during the analysis of the RIL population, additional bands linked to the tolerance loci were identified. This observation is consistent with the predicted power of NIL and RIL populations to detect QTL, which indicated that large RIL populations would usually be more sensitive than NILs for QTL detection (23). Even so, it was possible to prescreen AFLP primer combinations with just six lines to identify informative sets.

AFLP analysis is a very powerful technique for mapping genes controlling quantitatively inherited traits, especially when working with large populations and large numbers of markers. Numerous polymorphic bands were produced per assay without the need to generate specific probes. The results were quite reproducible. The polymorphisms observed in one population often were detected in the second and frequently were linked in the same order. These results are similar to those of Waugh et al. (57), which showed that many AFLP markers mapped to the same genetic loci in three different barley populations. The procedures were relatively easy compared with RFLP techniques and well-suited for analysis of quantitative traits with multiple populations. AFLP analysis requires only nanogram quantities of genomic DNA. Since the genomic DNA was digested with EcoRI and MseI, both of which have relatively common cutting sites, we were able to assign AFLP markers to 25 of the 37 oat RFLP segregation groups in the Kanota $\times$ Ogle RIL population (36) using only 15 primer combinations.

The combination of AFLP analysis and established RFLP maps was a very successful approach to identify and study QTL in oat in our study. To make the markers more useful in marker-assisted selection, we are attempting to convert the AFLP markers linked to the major BYDV-tolerance loci to nonradioactive PCR markers. Phenotypic selection for BYDV tolerance can be difficult given the complex interaction of host genes, viruses, vectors, and environmental conditions. With the use of DNA markers, it should be possible to identify lines containing the desirable alleles at all three major loci to accelerate the selection of breeding lines. In comparative mapping studies, homoeologous relationships have been identified among the chromosomes of diploid oat, barley, rice, wheat, and maize based on a common RFLP probes $(14,36,52,53)$. Since cultivated oats are hexaploid and have large complex genomes, the detailed map information available from barley, rice, and maize will be quite useful for the development of fine-scale maps of the tolerance loci, which may aid in the identification of markers even closer to the tolerance loci for both marker-assisted selection and the eventual cloning of the BYDV tolerance genes from oat.

\section{LITERATURE CITED}

1. Barua, U. M., Chalmers, K. J., Hackett, C. A., Thomas, W. T. B., and Powell, W. 1993. Identification of RAPD markers linked to a Rhynchosporium secalis resistance locus in barley using near-isogenic lines and bulked segregant analysis. Heredity 71:177-184.

2. Becker, J., Vos, P., Kuiper, M., Salamini, F., and Heun, M. 1995. Combined mapping of AFLP and RFLP markers in barley. Mol. Gen. Genet. 249:65-73.

3. Burnett, P. A., Comeau, A., and Qualset, C. O. 1995. Host plant tolerance or resistance for control of barley yellow dwarf. Pages 307-320 in: Barley Yellow Dwarf: 40 Years of Progress. C. J. D’Arcy and P. A. Burnett, eds. The American Phytopathological Society, St. Paul, MN.

4. Camargo, L. E. A., and Osborn, T. C. 1996. Mapping loci controlling flowering time in Brassica oleracea. Theor. Appl. Genet. 92:610-616.

5. Chalhoub, B. A., Sarrafi, A., and Lapierre, H. D. 1995. Partial resistance in the barley (Hordeum vulgare L.) cultivar 'Chikurin Ibaraki 1' to two PAV-like isolates of barley yellow-dwarf virus-Allelic variability at the Yd2 gene locus. Plant Breed. 114:303-307.

6. Cho, Y. G., Blair, M. W., Panaud, O., and McCouch, S. R. 1996. Cloning and mapping of variety-specific rice genomic sequences-Amplified fragment length polymorphisms (AFLP) from silver-stained polyacrylamide gels. Genome 39:373-378.

7. Cnops, G., Denboer, B., Gerats, A., Van Montagu, M., and Van Lijsebettens, M. 1996. Chromosome landing at the Arabidopsis TORNADO1 locus using an AFLP-based strategy. Mol. Gen. Genet. 253:32-41.

8. Collins, N. C., Paltridge, N. G., Ford, C. M., and Symons, R. H. 1996. The $Y d 2$ gene for barley yellow dwarf virus resistance maps close to the centromere on the long arm of barley chromosome 3. Theor. Appl. Genet. 92:858-864.

9. Concibido, V. C., Denny, R. L., Lange, D. A., Orf, J. H., and Young, N. D. 1996. RFLP mapping and marker-assisted selection of soybean cyst nematode resistance in PI 209332. Crop Sci. 36:1643-1650.

10. Concibido, V. C., Lange, D. A., Denny, R. L., Orf, J. H., and Young, N. D. 1997. Genome mapping of soybean cyst nematode resistance genes in 'Peking,' PI 90763, and PI 88788 using DNA markers. Crop Sci. 37:258-264.

11. Cooper, J. I., and Jones, A. T. 1983. Responses of plants to viruses: Proposals for the use of terms. Phytopathology 73:127-128.

12. D'Arcy, C. J. 1995. Symptomatology and host range of barley yellow dwarf. Pages 9-28 in: Barley Yellow Dwarf: 40 Years of Progress. C. J. D'Arcy and P. A. Burnett, eds. The American Phytopathological Society, St. Paul, MN.

13. DeloGu, G., Cattivelli, L., Snidaro, M., and Stanca, A. M. 1995. The Yd2 gene and enhanced resistance to barley yellow dwarf virus (BYDV) in winter barley. Plant Breed. 114:417-420.

14. Devos, K. M., and Gale, M. D. 1997. Comparative genetics in the grasses. Plant Mol. Biol. 35:3-15.

15. Doyle, J. J., Doyle, J. L., and Bailey-Hortorium, L. H. 1990. Isolation of plant DNA from fresh tissue. Focus 12:13-15.

16. Folkertsma, R. T., Vandervoort, J. N. A. M. R., Degroot, K. E., Vanzandvoort, P. M., Schots, A., Gommers, F. J., Helder, J., and Bakker, J. 1996. Gene pool similarities of potato cyst nematode populations assessed by AFLP analysis. Mol. Plant-Microbe Interact. 9:47-54.

17. Gray, S. M., Smith, D., and Altman, N. 1993. Barley yellow dwarf virus isolate-specific resistance in spring oats reduced virus accumulation and aphid transmission. Phytopathology 83:716-720.

18. Harder, D. E., and Harber, S. 1992. Barley yellow dwarf virus. Page 379 
in: Oats Science and Technology. H. G. Marshall and M. E. Sorrells, eds. American Society of Agronomy, Inc, Madison, WI.

19. Hewings, A. D., Kolb, F. L., Gregerson, G. R., and Bauske, E. M. 1992. Field research and germplasm evaluation methodology for barley yellow dwarf virus in cereals. Pages 44-46 in: Proc. Int. Oat Conf., 4th.

20. Hill, M., Wisenboer, H., Zabeau, M., Vos, P., Kesseli, R., and Michelmore, R. 1996. PCR-based fingerprinting using AFLPs as a tool for studying genetic relationships in Lactuca spp. Theor. Appl. Genet. 93:1202-1210.

21. Holland, J. B., Moser, H. S., O'Donoughue, L. S., and Lee, M. 1997. QTLs and epistasis associated with vernalization responses in oat. Crop Sci. 37:1306-1316.

22. Holloway, P. J., and Heath, R. 1992. Identification of polypeptide markers of barley yellow dwarf virus resistance and susceptibility genes in non-infected barley (Hordeum vulgare) plants. Theor. Appl. Genet. 85: 346-352.

23. Kaeppler, S. M. 1997. Quantitative trait locus mapping using sets of near-isogenic lines: relative power comparisons and technical considerations. Theor. Appl. Genet. 95:384-392.

24. Kianian, S. F., Wu, B. C., Fox, S. L., Rines, H. W., and Phillips, R. L. 1997. Aneuploid marker assignment in hexaploid oat with the $C$ genome as a reference for determining remnant homoeology. Genome 40:386-396.

25. Lander, E. S., Green, P., Abrahamson, J., Barlow, A., Daly, M. J., Lincoln, S. E., and Newburg, L. 1987. MAPMAKER: an interactive computer package for constructing primary genetic linkage maps of experimental and natural populations. Genomics 1:174-181.

26. Landry, B., Comeau, A., Minvielle, F., and St-Pierre, C.-A. 1984. Genetic analysis of resistance to barley yellow dwarf virus in hybrids between Avena sativa 'Lamar' and virus-resistant lines of Avena sterilis. Crop Sci. 24:337-340.

27. Large, E. G. 1954. Growth stages in cereals: Illustration of the Feeke's scale. Plant Pathol. 3:128-129.

28. Lincoln, S., Daly, M., and Lander, E. 1992. Mapping genes controlling quantitative traits with MAPMAKER/QTL 1.1. A Whitehead Institute for Biomedical Research Technical Report, Cambridge, MA.

29. Mackill, D. J., Zhang, Z., Redoña, E. D., and Colowit, P. M. 1996. Level of polymorphism and genetic mapping of markers in rice. Genome 39: 969-977.

30. Martin, G. B., Williams, J. G., and Tanksley, S. D. 1991. Rapid identification of markers linked to a Pseudomonas resistance gene in tomato by using random primers and near-isogenic lines. Proc. Natl. Acad. Sci. U.S.A. $88: 2336-2340$.

31. Maughan, P. J., Maroof, M. A. S., Buss, G. R., and Huestis, G. M. 1996. Amplified fragment length polymorphism (AFLP) in soybean-Species diversity, inheritance, and near-isogenic line analysis. Theor. Appl. Genet. 93:392-401.

32. McKenzie, R. I. H., Burnett, P. A., Gill, C. C., Comeau, A., and Brown, P. D. 1985. Inheritance of tolerance to barley yellow dwarf virus in oats. Euphytica 34:681-687.

33. Nelson, J. C. 1997. QGENE: Software for marker-based genomic analysis and breeding. Mol. Breed. 3:239-245.

34. Nyquist, W. E. 1991. Estimation of heritability and predicting of selection response in plant populations. Crit. Rev. Plant Sci. 10:235-322.

35. O'Donoughue, L. S., Chong, J., Wight, C. P., Fedak, G., and Molnar, S. J. 1996. Localization of stem rust resistance genes and associated molecular markers in cultivated oat. Phytopathology 86:719-727.

36. O'Donoughue, L. S., Kianian, S. F., Rayapati, P. J., Penner, G. A., Sorrells, M. E., Tanksley, S. D., Phillips, R. L., Rines, H. W., Lee, M., Fedak, G., Molnar, S. J., Hoffman, D., Salas, C. A., Wu, B., Autrique, E., and Van Deynze, A. 1995. A molecular linkage map of cultivated oat. Genome 38:368-380.

37. Paul, S., Wachira, F. N., Powell, W., and Waugh, R. 1997. Diversity and genetic differentiation among populations of Indian and Kenyan tea (Camllia sinensis (L.) O. Kuntze) revealed by AFLP markers. Theor. Appl. Genet. 94:255-263.

38. Powell, W., Morgante, M., Andre, C., Hanafey, M., Vogel, J., Tingey, S., and Rafalski, A. 1996. The comparison of RFLP, RAPD, AFLP, and SSR (microsatellite) markers for germplasm analysis. Mol. Breed. 2:225-238.

39. Qualset, C. O. 1984. Evaluation and breeding methods for barley yellow dwarf resistance. Pages 72-80 in Barley Yellow Dwarf Virus, A Proceeding of the Workshop. 1984. CIMMYT, Mexico D.F., Mexico.

40. Ray, J. D., Yu, L., McCouch, S. R., Champoux, M. C., Wang, G., and Nguyen, H. T. 1996. Mapping quantitative trait loci associated with root penetration ability in rice (Oryza sativa L.). Theor. Appl. Genet. 92:627-636.

41. Redoña, E. D., and Mackill, D. J. 1996. Mapping quantitative trait loci for seedling vigor in rice using RFLPs. Theor. Appl. Genet. 92:395-402.

42. Sarfatti, M. M., Abuabied, J. K., and Zamir, D. 1991. RFLP mapping of I1, a new locus in tomato conferring resistance against Fusarium oxysporium f. sp. Lycopersici race-1. Theor. Appl. Genet. 82:22-26.

43. Schaller, C. W., Qualset, C. O., and Rutger, J. N. 1964. Inheritance and linkage of the $Y d 2$ gene conditioning resistance to the barley yellow dwarf virus in barley. Crop Sci. 4:544-548.

44. Schondelmaier, J., Steinrucken, G., and Jung, C. 1996. Integration of AFLP markers into a linkage map of sugar beet (Beta vulgaris L.). Plant Breed. 115:231-237.

45. Simons, G., van der Lee, T., Diergaarde, P., van Daelen, R., Groenendijk, J., Frijters, A., Buschges, R., Hollricher, K., Topsch, S., Schulze-Lefert, P., Salamini, F., Zabeau, M., and Vos, P. 1997. AFLP-based fine mapping of the Mlo gene to a 30-kb DNA segment of the barley genome. Genomics 44:61-70

46. Singh, R. P., Burnett, P. A., Albarran, M., Rajaram, S. 1993. BDV1-A gene for tolerance to barley yellow dwarf virus in bread wheats. Crop Sci. 33:231-234.

47. Siripoonwiwat, W., O'Donoughue, L. S., Wesenberg, D., Hoffman, D. L., Barbosa-Neto, J. F., and Sorrells, M. E. 1996. Chromosomal regions associated with quantitative traits in oat. J. Quant. Trait Loci 2: Article 3. Crop Science Society of America, Madison, WI.

48. Suneson, C. A. 1955. Breeding for resistance to yellow dwarf virus in barley. Agron. J. 47:283.

49. Tanksley, S. D. 1993. Mapping Polygenes. Annu. Rev. Genet. 27:205-233.

50. Thomas, C. M., Vos, P., Zabeau, M., Jones, D. A., Norcott, K. A., Chadwick, B. P., and Jones, J. D. G. 1995. Identification of amplified restriction fragment polymorphism (AFLP) markers tightly linked to the tomato $C f$ 9 gene for resistance to Cladosporium fulvum. Plant J. 8:785-794.

51. Tohme, J., Gonzalez, D. O., and Beebe, S. 1996. AFLP analysis of gene pools of a wild bean core collection. Crop Sci. 36:1375-1384.

52. Van Deynze, A. E., Nelson, J. C., O’Donoughue, L. S., Ahn, S. N., Siripoonwiwat, W., Harrington, S. E., Yglesias, E. S., Braga, D. P., McCouch, S. R., and Sorrells, M. E. 1995. Comparative mapping in grasses-oat relationships. Mol. Gen. Genet. 249:349-356.

53. Van Deynze, A. E., Nelson, J. C., Yglesias, E. S., Harrington, S. E., Braga, D. P., McCouch, S. R., and Sorrells, M. E. 1995. Comparative mapping in grasses-wheat relationships. Mol. \& Gen. Genet. 248:744-754.

54. Vaneck, H. J., Vandervoort, J. R., Draaistra, J., Vanzandvoort, P., Vanenckevort, E., Segers, B., Peleman, J., Jacobsen, E., Helder, J., and Bakker, J. 1995. The inheritance and chromosomal localization of AFLP markers in a non-inbred potato offspring. Mol. Breed. 1:397-410.

55. VanToai, T. T., Peng, J., and St. Martin, S. K. 1997. Using AFLP markers to determine the genomic contribution of parents to populations. Crop Sci. 37:1370-1373.

56. Vos, P., Hogers, R., Bleeker, M., Reijans, M., Vandelee, T., Hornes, M., Frijters, A., Pot, J., Peleman, J., Kuiper, M., and Zabeau, M. 1995. AFLPA new technique for fingerprinting. Nucleic Acids Res. 23:4407-4414.

57. Waugh, R., Bonar, N., Baird, E., Thomas, B., Graner, A., Hayes, P., and Powell, W. 1997. Homology of AFLP products in three mapping populations of barley. Mol. Gen. Genet. 255:311-321.

58. Xiao, J., Li, J., Yuan, L., and Tanksley, S. D. 1996. Identification of QTLs affecting traits of agronomic importance in a recombinant inbred population derived from a subspecific rice cross. Theor. Appl. Genet. 92: 230-244

59. Young, N. D. 1996. QTL mapping and quantitative disease resistance in plants. Annu. Rev. Phytopathol. 34:479-501. 